Review

\title{
Alzheimer's Disease: Is a Dysfunctional Mevalonate Biosynthetic Pathway the Master-Inducer of Deleterious Changes in Cell Physiology?
}

\author{
Arnold De Loof ${ }^{*}$, Liliane Schoofs
}

Functional Genomics and Proteomics Group, Department of Biology, KU Leuven, Belgium; E-Mails: arnold.deloof@bio.kuleuven.be; liliane.schoofs@kuleuven.be

* Correspondence: Arnold De Loof; E-Mail: arnold.deloof@bio.kuleuven.be

\section{Academic Editor: Golam Sharoar}

Special Issue: Alzheimer's Disease Research

\section{OBM Neurobiology}

2019 , volume 3 , issue 4

doi:10.21926/obm.neurobiol.1904046
Received: October 03, 2019

Accepted: November 15, 2019

Published: November 29, 2019

\begin{abstract}
There is a growing awareness that the proteins-amyloid-beta $(A \beta)$ and tau-do not cause Alzheimer's disease (AD) but are produced as a result of it. Similarly, doubt reigns over the degree of causality of high plasma cholesterol and prenylation in AD. This review proposes a fresh and important perspective, in addition to the current line of thinking. It emerges from comparative analysis, in evolutionary retrospect, of the characteristics of the mevalonate biosynthetic pathways in insects versus vertebrates, and of the drastic effects of the absence of farnesol and its esters with juvenile hormone (JH) activity. A dysfunctional mevalonate biosynthetic pathway, with farnesol at its very heart, can disturb "Golgicrine" activity, reduce mitochondrial multiplication, alter $\mathrm{Ca}^{2+}$ homeostasis, and cause massive apoptosis in specific tissues. These effects were observed in insects in the 1960-70s. It became undeniably established that the absence of endogenous sesquiterpenoids farnesol and its $\mathrm{JH}$ esters is the direct inducer of complete metamorphosis. Such effects are remarkably similar in metamorphosing insects and in the brain with $A D$. In insects, the administration of farnesol/JH temporarily prevents all mentioned changes. The absence of farnesol/JH was not observed in insects with incomplete metamorphosis; hence, there is no massive apoptosis. Neither do vertebrates have a period in their development in which the mevalonate
\end{abstract}

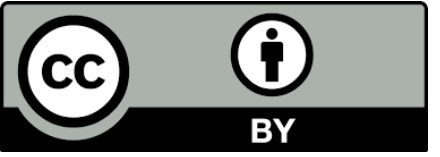
conditions of the Creative Commons by Attribution License, which permits unrestricted use, distribution, and reproduction in any medium or format, provided the original work is correctly cited. 
biosynthetic pathway - that synthesizes farnesyl pyrophosphate, farnesol, and cholesterolcomes to a complete halt. Hence, there exists a difficulty in uncovering the other functions of farnesol, besides being an intermediate in the mevalonate pathway. A major breakthrough was achieved in 1999 with the discovery that farnesol in rodent and human brains potently blocks $\mathrm{N}$-type $\mathrm{Ca}^{2+}$ channels. It was proved that the mevalonate pathway and farnesol play key roles in $\mathrm{Ca}^{2+}$ homeostasis. This paper highlights the major consequences of this chemical/pathway in AD research.

\section{Keywords}

Apoptosis; neurodegeneration; juvenile hormone; programmed cell death; metamorphosis; diapause; Golgi system; amyloid; tau; Golgicrine

\section{Introduction}

The occurrence of the first biochemical changes, leading to the behavioral symptoms of Alzheimer's disease (AD), is unknown. Some researchers anticipate that these changes occur long before the behavioral symptoms are recognized, probably several years or decades prior. Hence, it may be impossible to perform biochemical analyses of the brains of a sufficiently large group of symptom-free potential AD patients and to follow them for years. Mouse models are widely used in studying the causes of and the cures for Alzheimer's disease [1, 2], but these studies have not yet yielded the required breakthroughs in this field. Studies in invertebrate animal models, such as insects (Drosophila spp. [2-4]) and nematode worms (Caenorhabditis elegans [5]), are less accepted. This is mainly because such animals do not live long enough to get sick and die from prominent degenerative brain diseases. Yet, such simplistic reasoning overlooks the possibility that the molecular signaling pathways, underlying initiation of Alzheimer's disease, may be present in short-living, invertebrate animals or even in yeast. In this review, we focus on the mevalonate biosynthetic pathway, with a special focus on farnesol [2] as a possible and evolutionarily ancient mechanism for inducing massive apoptosis, a symptom in the late stage of Alzheimer's disease.

However, why should we focus specifically on farnesol? Because of the well-documented role of farnesol and its esters with juvenile hormone activity, also called farnesol-like endogenous sesquiterpenoids (FLS), in inducing "Alzheimer's disease-like symptoms" in pre-diapausing and metamorphosing insects [6-8]. These symptoms do not manifest themselves in the brains but in other tissues. This is not due to the presence of excess farnesol/FLS but because they cause such effects when their concentrations in the body fall to very low values, even reaching zero. Such a drastic fall in titer does not occur in vertebrate development. Hence, the effects of a defective mevalonate pathway were never observed in vertebrates, with no reason to causally link farnesol to Alzheimer's disease.

\section{Farnesol, the "Noble Unknown", a Key Molecule in Cell Physiology}

\subsection{Farnesol: A Sesquiterpenoid}


Farnesol is a natural, 15-carbon, acyclic sesquiterpene alcohol (Figure 1B). Around 1900, it was originally extracted by perfume makers from the acacia tree, Vachellia farnesiana (Figure 2); hence, the name was given [9]. Sesquiterpenes are a class of terpenes that consist of three isoprene units and often have the molecular formula $\mathrm{C}_{15} \mathrm{H}_{24}$. Isoprene, or 2-methyl-1,3-butadiene, is a common organic compound with the formula $\mathrm{CH}_{2}=\mathrm{C}\left(\mathrm{CH}_{3}\right)-\mathrm{CH}=\mathrm{CH}_{2}$ (Figure $1 \mathrm{~A}$ ). Two identical farnesyl pyrophosphate (farnesyl-PP) molecules can enzymatically be converted to form the 30carbon squalene. Squalene is a precursor for cholesterol in animals and for steroids in plants, animals, and fungi (Figure 3). Under standard conditions, farnesol and FLS are colorless liquids. They are hydrophobic, and thus poorly soluble in water but miscible with oils [10]. Farnesol occurs in several isomeric forms with differential potency in some bioassays (PubChem). It has seven rotatable bonds, making it an extremely flexible molecule. It takes a horseshoe shape (Figure 1C). These properties are probably important for its function in prenylation, a key phenomenon in the functioning of G protein Coupled Receptors (GPCRs) and in binding to receptor-pockets in helixbundle transmembrane proteins [11]. Defective prenylation may play a role in Alzheimer's disease. De Araújo Delmondes et al. provided a summary of the toxicological and pharmacological effects of farnesol [12].

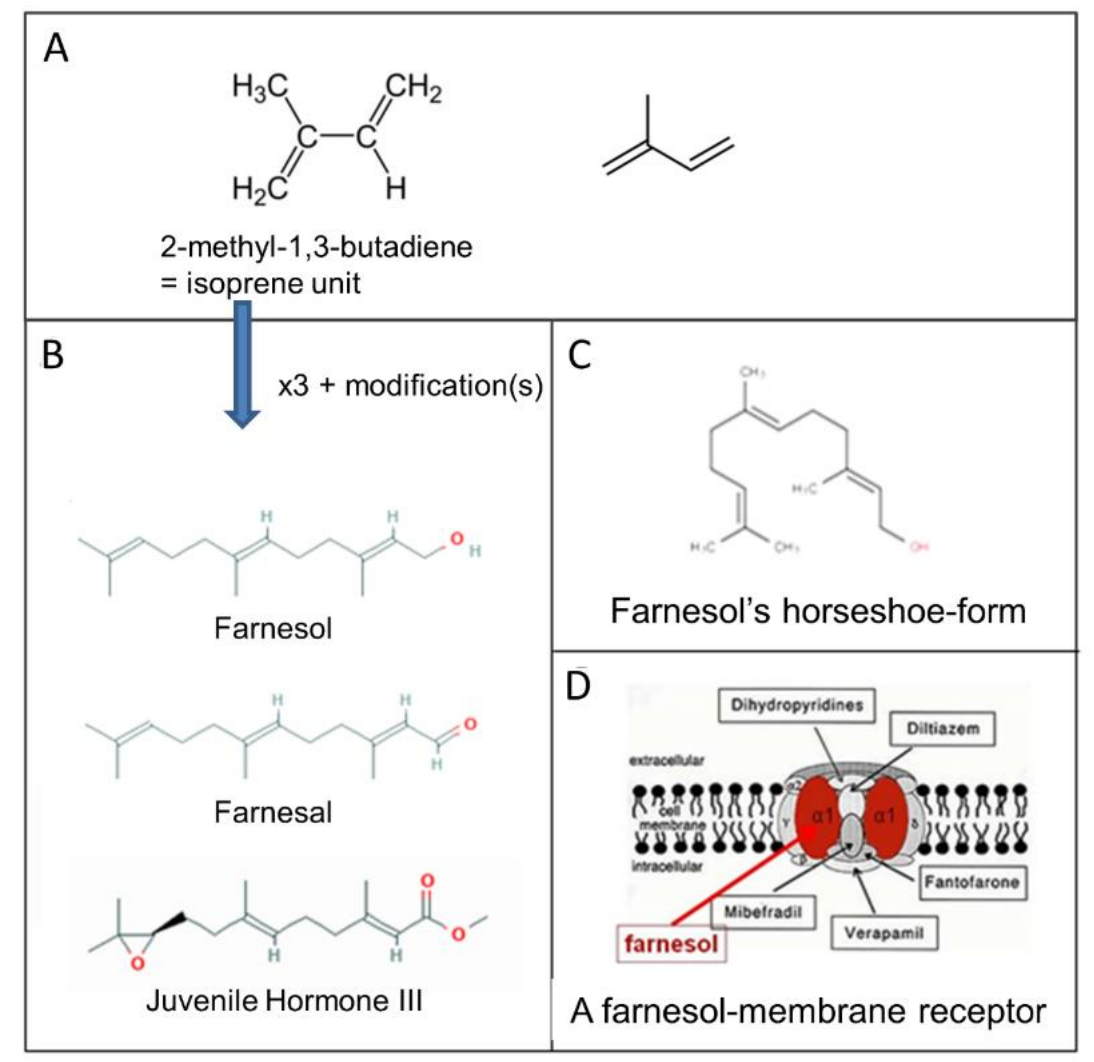

Figure 1 The chemical structure of farnesol and its derivatives. A. Chemical structure of isoprene or 2-methyl-1,3-butadiene, the basic building block of sesquiterpenoids. B. Chemical structure of the sesquiterpenoids-farnesol, farnesal, and juvenile hormones - synthesized from isoprene unit as their building block [10,13]. C. Farnesol and its $\mathrm{JH}$ esters display high flexibility and have a horseshoe-form. D. Some types of membrane channels (e.g., $\mathrm{Ca}^{2+}$ channels) act as receptors for farnesol [14]. All Open Access. 


\subsection{Farnesol Occurrence in All Eukaryotes}

Farnesol, for more than a century, has been best known as a perfume ingredient occurring in floral extracts. However, in the 1960s, Peter Schmialek extracted farnesol and farnesal from excrements of the mealworm, Tenebrio molitor, in his search for the chemical nature of "juvenile hormone" $(\mathrm{JH})$ in insects $[15,16]$. For the first time, he determined the chemical identity of these compounds in an "animal context", and found them to display JH activity $[6,11]$.

With the advent of improved methods for identification of farnesol and FLS, it became evident that farnesol is present in all eukaryotes, and probably in a few prokaryotes. The mevalonate biosynthetic pathway that forms farnesol is present in all eukaryotes, including humans ( $\S 3$ ). This suggests that this biosynthetic pathway may have an important function in cell physiology. However, uncovering its functions proceeded relatively faster in insects, but not in vertebrates [6, 17].

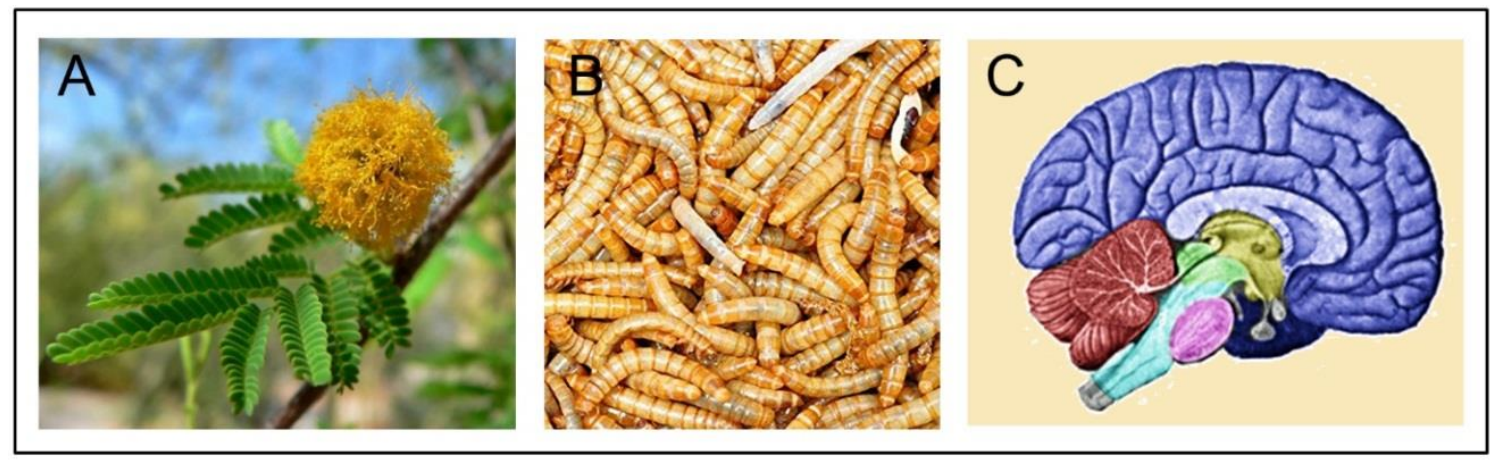

Figure 2 Farnesol is omnipresent in eukaryotes. A. Farnesol, derived from the plant, Vachellia farnesiana, is widely used in the perfume industry [9]. B. Larvae of the mealworm, Tenebrio molitor [18], the first identified animal source of farnesol [15] (from Google pictures - Proteinsecta). C. Along with its mevalonate biosynthetic pathway, farnesol is present in all eukaryotes, including the human brain (Google Images). All Open Access.

\section{The Essence of Mevalonate Biosynthetic Pathway in an Evolutionary Retrospect}

\subsection{Dichotomy in the Mevalonate Pathway}

Comparing evolutionarily distant groups of animals, such as sponges, insects, and humans, revealed that the basic signaling pathways have been remarkably conserved; since their common descent. This certainly holds true for the vital, but relatively neglected, mevalonate biosynthetic pathway (Figure 3). This pathway operates in all eukaryotes - unicellular and multicellular, across animals, plants, and fungi-though, not always in the same way.

There is a dichotomy. In vertebrates, including humans, the mevalonate pathway leads to the biosynthesis of farnesol, cholesterol, and steroids, but not to that of farnesol esters with $\mathrm{JH}$ activity. In ecdysozoans, such as insects and nematodes, it leads to the synthes is of farnesol and its esters with $\mathrm{JH}$ activity, but not to that of cholesterol and steroids, due to lack of the gene for squalene synthase enzyme. Because of these differences, it can be inferred that the most ancient function of the mevalonate pathway was not for the biosynthesis of squalene, cholesterol, or JH. 


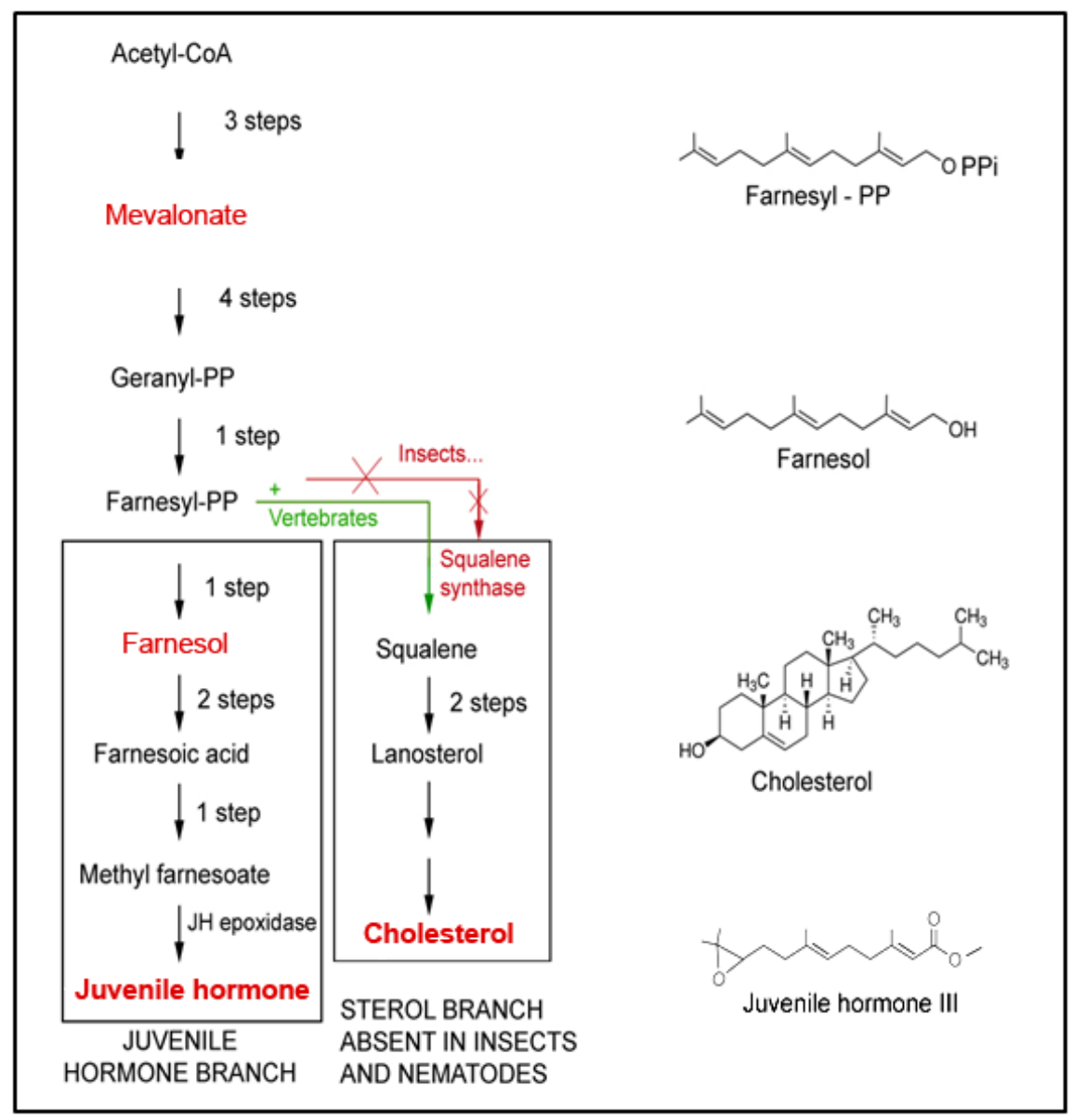

Figure 3 The mevalonate biosynthetic pathway. The initial steps up to the synthesis of farnesyl-PP and farnesol are identical in insects and vertebrates. Subsequent steps are different. Because ecdysozoans (arthropods and nematodes) do not have the gene coding for squalene synthase, they cannot synthesize squalene and cholesterol. They acquire cholesterol from food sources or by metabolization of some (ecdy)steroids. Insects can also make esters of farnesol, the juvenile hormones (JHs). Vertebrates do not make JHs, but some plants do. Image adapted from [19, 20].

\subsection{The Evolutionarily Primordial Function of the Mevalonate Pathway}

In recent years, there has been a growing consensus that the primordial function of the mevalonate pathway is the one that is still present in all eukaryotes, namely, the production of farnesol. It not only acts as an intermediate in the pathway but also has a key role in controlling $\mathrm{Ca}^{2+}$ homeostasis $[6,11,17]$. This novel insight was a result of the identification of a membrane receptor of farnesol that also acts as a $\mathrm{Ca}^{2+}$ channel $[21,22](\S 5)$. An intracellular concentration of $\mathrm{Ca}^{2+}$ beyond a certain threshold may be toxic to the cells and needs to be countered in one or more ways (§7.2).

\section{Farnesol in the Human Brain}

According to Roullet et al. [21], farnesol occurs naturally in human and rodent brain tissues. The all-trans-farnesol stereoisomer was identified; whereas, the cis,trans-farnesol isomer was not 
detectable. Farnesol concentrations were estimated to range from 373 to $417 \mathrm{pmol} / \mathrm{g}$ wet weight. The concentrations in young rat brains were around $590 \mathrm{pmol} / \mathrm{g}$ wet weight. They also analyzed frontal cortex samples from four humans (46 years or older), who died from different causes, less than $24 \mathrm{~h}$ post mortem. All the necropsy specimens contained all-trans-farnesol in the range from 110 to $290 \mathrm{pmol} / \mathrm{g}$ fresh weight, with no detectable cis,trans-farnesol. In addition to brains in rats, farnesol was also reported to be present in blood and prostate glands [17].

\section{The Functional Link between the Mevalonate Pathway and $\mathrm{Ca}^{2+}$ Homeostasis}

About 20 years ago, farnesol was not even considered to have any role in cell physiology, let alone being an intermediate in the biosynthesis of squalene and JHs. That changed when electrophysiologists, Roullet [21] and Luft [22], reported that farnesol acts as an endogenous, potent blocker of $\mathrm{N}$-type $\mathrm{Ca}^{2+}$ channels, in rodents and humans. This linked the endogenous sesquiterpenoids - farnesol and FLS-to $\mathrm{Ca}^{2+}$ homeostasis, which, like the mevalonate pathway, is highly conserved and multifunctional in all eukaryotes. The second argument in favor of important roles of farnesol and its esters comes from the observation that the SERCA blocker, thapsigargin, and the absence of farnesol/JH induce apoptosis in insects. Chemically, thapsigargin and farnesol/JHs belong to the family of sesquiterpenoids. The binding of thapsigargin to SERCA illustrates that SERCA has a binding site for sesquiterpenoids [23, 24]. The natural, endogenous ligand has not yet been identified with certainty, despite intensive research efforts. One hypothesis states that thapsigargin may displace a natural sesquiterpenoid ligand from its binding site. Farnesol and FLS, the most abundant sesquiterpenoids in animals, are prime candidates. Like during the onset of insect metamorphosis, their biosynthesis may be inactivated, or it may be completely eliminated by the surgical removal of the glands, corpora allata (CA); that produce them. The argument is that the absence of farnesol/JH, as mentioned above, induces apoptosis, just like in the case of thapsigargin administration. Programmed cell death or apoptosis is causally linked to increased intracellular concentrations of $\mathrm{Ca}^{2+}[25]$.

\section{Basic Principles of Intracellular $\mathrm{Ca}^{2+}$ Homeostasis}

\subsection{Beneficial and Toxic $\mathrm{Ca}^{2+}$}

In order to understand our argumentation for the role of farnesol and FLS in bringing about physiological effects, one should be familiar with the principles of intracellular $\mathrm{Ca}^{2+}$ homeostasis (Figure 4). In physiology, $\mathrm{Ca}^{2+}$ is best known for its beneficial functions - as a building block in endo- and exoskeletons, in muscle contraction, in the functioning of neurons, and as an intracellular secondary messenger of many signaling systems, to name a few. This contrasts with the counterintuitive fact that $\mathrm{Ca}^{2+}$ is the most abundant toxin on earth and its toxicity (at rising cytoplasmic concentrations) forms the basis for the mentioned beneficial effects [26]. Variations in intracellular concentrations of $\mathrm{Ca}^{2+}$, like $\mathrm{H}^{+}$, cause changes in the 3D structure and activity of a variety of macromolecules, in particular of proteins and enzymes. For example, a higher concentration of $\mathrm{Ca}^{2+}$ in cytoplasm leads to muscle contraction. Similarly, subtle changes in $\mathrm{Ca}^{2+}$ concentrations can induce apoptosis. De Loof et al. provided a concise overview of the principles of intracellular $\mathrm{Ca}^{2+}$ homeostasis [26]. 


\section{$6.2 \mathrm{Ca}^{2+}$ Gradients over the Membrane-Limited (Intracellular) Compartments}

It is important to keep in mind that intracellular $\mathrm{Ca}^{2+}$ is not homogenously distributed. Different membrane-limited intracellular compartments have different $\mathrm{Ca}^{2+}$ concentrations, which can be much higher than that in the cytoplasm (Figure 4A).

Under resting conditions, the intracellular concentration of free $\mathrm{Ca}^{2+}\left(\left[\mathrm{Ca}^{2+}\right]_{i}\right)$ is very low, about $100 \mathrm{nM}$, compared to the average extracellular concentration of around $2 \mathrm{mM}$, with up to $50 \mathrm{mM}$ in milk $\left(>10,000 \times\right.$ higher). This means that there is a constant force acting on extracellular $\mathrm{Ca}^{2+}$ to enter the cells. The biological membranes are impermeable for $\mathrm{Ca}^{2+}$ ions. They can enter or leave the cells only if integral membrane proteins, such as $\mathrm{Ca}^{2+}$-transporters are present and operational. For example, $\mathrm{Ca}^{2+}$ ATPases actively transport the ions against an existing $\mathrm{Ca}^{2+}$ gradient, and $\mathrm{Ca}^{2+}$ channels passively transport the ions down an existing gradient.

The key function of the integrated $\mathrm{Ca}^{2+}$ homeostasis system is to maintain a low $\left[\mathrm{Ca}^{2+}\right]_{i}$ under a threshold value, beyond which it becomes toxic. This toxicity threshold is as low as $100 \mathrm{nM}$. Cells have several mechanisms that help keep the cytoplasmic $\left[\mathrm{Ca}^{2+}\right]_{i}$ below this low toxicity value (Figure 4).

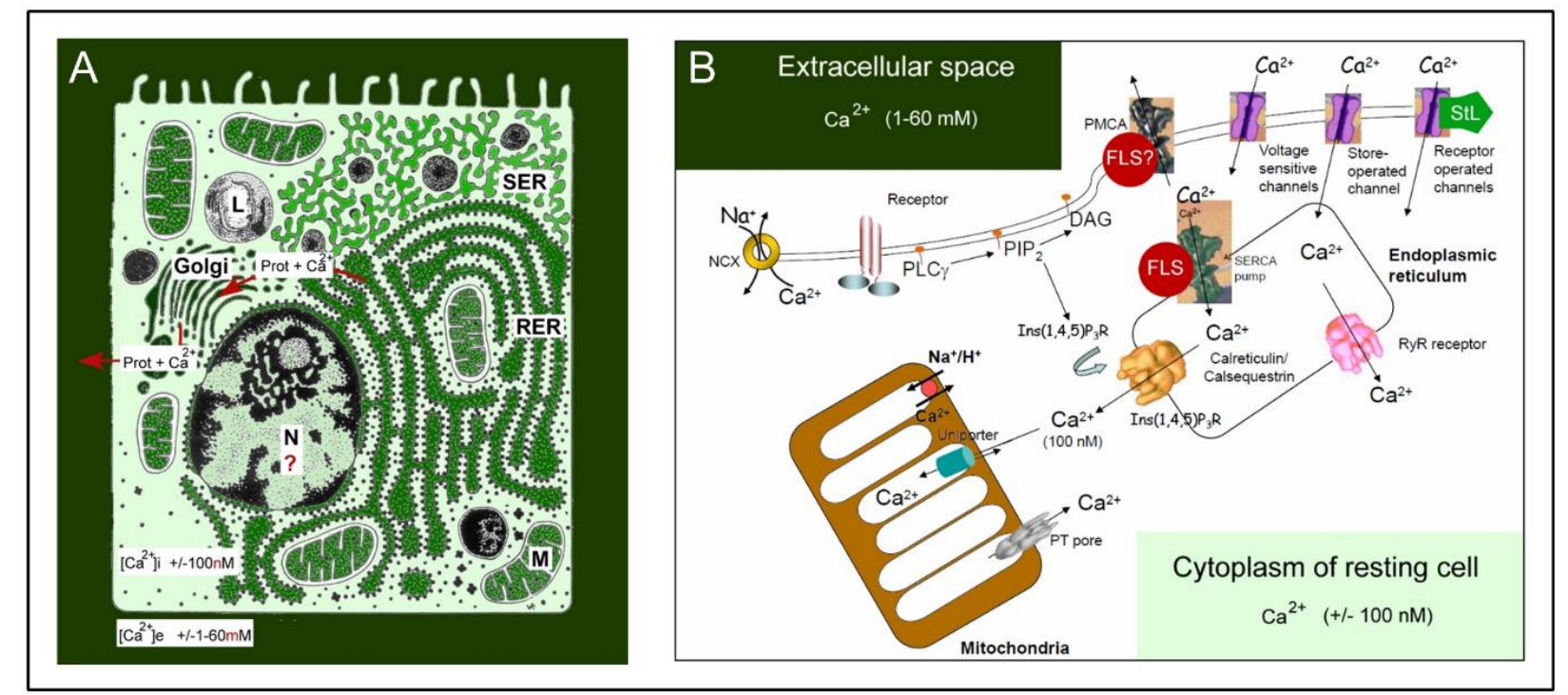

Figure 4 Schematic representation of the $\mathrm{Ca}^{2+}$ gradients in and around the Cell. A. The different shades of green, though not to scale, represent relative differences in $\mathrm{Ca}^{2+}$ concentration in the extracellular region and in various intracellular compartments lysosome (L), mitochondria (M), rough endoplasmic reticulum (RER), smooth endoplasmic reticulum (SER), and possibly nucleus (N). The abundance of SER and RER in cells provides a first indication on the importance of the $\mathrm{Ca}^{2+}$-homeostasis system for the functioning of cells, in particular for removing excess $\mathrm{Ca}^{2+}$ through the RER-Golgi system, and for inhibition of some enzyme systems. This is due to the fact that the SER and RER are membrane systems in which numerous enzymes are anchored, such as those involved in the synthesis of lipids, steroids, and proteins. Their activities are partially controlled by the $\mathrm{Ca}^{2+}$ gradient across membranes. From [26], Open Access. B. This figure lists the main players in the $\mathrm{Ca}^{2+}$ homeostasis/extrusion system except for the Golgi complex, which is also important for $\mathrm{Ca}^{2+}$-extrusion (this paper). Because the 
explanatory text in the cited paper [25] is rather long, we do not repeat it here. This figure is borrowed from earlier works [20, 25] with copyright permission for both, figure and legend, from the publisher and from authors.

Several factors govern which element of the finely tuned $\mathrm{Ca}^{2+}$ homeostasis system is activated, upon elevation of $\left[\mathrm{Ca}^{2+}\right]_{i}$. Two major factors are cell type and amount of $\mathrm{Ca}^{2+}$ entering the cell. For example, some steroid hormones, such as female sex steroids (estrogen in vertebrates and 20hydroxyecdysone in insects), promote the influx of $\mathrm{Ca}^{2+}$ into target cells that have membrane receptors for such steroids. On the other hand, farnesol and FLS help to keep $\left[\mathrm{Ca}^{2+}\right]_{i}$ low, thereby maintaining the larval stage (formerly called the status quo) of development in insects.

\subsection{Removal of Excess $\mathrm{Ca}^{2+}$ from Cells: Basic Mechanisms}

Evidently, the best mechanism to keep the $\left[\mathrm{Ca}^{2+}\right]_{i}$ low is to make the plasma membrane as impermeable as possible to $\mathrm{Ca}^{2+}$. This can be realized by having fewer $\mathrm{Ca}^{2+}$ channels and by restricting the time they are open by controlling their gating mechanisms. In the case of excess $\mathrm{Ca}^{2+}$ enters the cell, plasma membrane $\mathrm{Ca}^{2+}$-ATPases (PMCAs) are activated to remove $\mathrm{Ca}^{2+}$ from the cell. When the influx of $\mathrm{Ca}^{2+}$ exceeds the pumping out by the PMCAs, rescuing is needed. One of the mechanisms is to store a limited amount of excess $\mathrm{Ca}^{2+}$ in intracellular storage sites. These include the mitochondria and the lumina of the endoplasmic reticulum (ER), in particular the smooth ER (SER).

In some cell types, the influx of $\mathrm{Ca}^{2+}$ can be high. For example, under the influence of female sex steroids, the permeability of the plasma membrane to $\mathrm{Ca}^{2+}$ increases by the opening of the membrane G-protein coupled estrogen receptors [27]. As a result, the combined efforts of the $\mathrm{Ca}^{2+}$-ATPases in the plasma membrane and the temporary storage of $\mathrm{Ca}^{2+}$ in the SER and mitochondria do not always suffice for neutralizing the increasing $\left[\mathrm{Ca}^{2+}\right]_{i}$. In such a case, the rough ER (RER) gets involved, as discussed below. If all aforementioned mechanisms fail, $\mathrm{Ca}^{2+}{ }^{2}$-induced apoptosis gets activated [25]. For introductory figures on this topic, see [28].

\subsection{Golgicrine Activity of Cargo Proteins, $\mathrm{Ca}^{2+}$, and Farnesol/FLS: Novel Insights}

\subsubsection{Physiology Underlying the Secretion of Cargo Proteins: Refrain from Invoking an Evolutionary Goal}

The rough endoplasmic reticulum (RER), in concert with the Golgi complex, secretes proteins with functions outside the cell, referred to as "cargo proteins". This is the best documented function. It is less well known that this system also provides a salient solution to the problem of excess intracellular $\mathrm{Ca}^{2+}$, before it induces apoptosis. Indeed, the RER-Golgi complex secretory system removes excess cytoplasmic $\mathrm{Ca}^{2+}$ along with the $\mathrm{Ca}^{2+}$-binding/transporting cargo proteins $[26,29,30]$. In addition, while it had always been assumed that farnesol and JHs leave the producing cells through simple diffusion, the idea is emerging that this may be incorrect. The possibility exists that release of JH (and of ecdysteroids as well) may also happen through the Golgi system (De Loof and Schoofs, in preparation). We introduce the term "Golgicrine activity" to denote the totality of the secretory activity of the RER-Golgi system. Some tissues are highly specialized for such secretory activities. The liver of vertebrates is a major site for the synthesis of 
proteins secreted into the blood. The fat body in insects, which is to some extent the functional counterpart of the vertebrate liver, also actively secretes proteins. Various other tissues and cell types secrete proteins, such as digestive enzymes, mucus, proteins of the accessory reproductive glands, proteins of the integument, protein and peptide hormones, and many more.

A question seldom asked is why these cells synthesize proteins that are of no immediate use to them. For example, cuticular proteins produced by epidermal cells, milk proteins by mammary glands, and silk proteins by silk glands are all secreted, but not beneficial to the cells producing them. One could argue that the secretion of such proteins increases the fitness of the animal secreting them or even another animal (milk feeds the young one); therefore, the protein secretion machinery is conserved in evolution. That is evidently true, but it neglects the fact that the protein-producing cells cannot "know" that the proteins they secrete will be beneficial for the organism by serving a role in nutrition, signaling, or protection. Indeed, such knowledge would mean that there is a goal in both the physiology of the cell and in evolution of the population, which is not the case.

Another explanation is that the secretory activity of the RER-Golgi complex system serves the primordial function of removing excess $\mathrm{Ca}^{2+}$ from the cytoplasm. This is especially vital when $\mathrm{Ca}^{2+}$ reaches extremely high concentrations to be removed by the $\mathrm{Ca}^{2+}$-ATPase pumps or by temporary $\mathrm{Ca}^{2+}$ storage in the organelles. This situation is well illustrated in mammals. Milk contains an extraordinarily high $\mathrm{Ca}^{2+}$ concentration of about $50 \times 10^{-3} \mathrm{M}$ versus a basic $\mathrm{Ca}^{2+}$ concentration of only $100 \times 10^{-9} \mathrm{M}$ inside the unstimulated cells. This results from the drastic increase in $\mathrm{Ca}^{2+}$ influx in mammary gland cells, under the influence of several hormones-specifically, prolactin and oxytocin. Under these circumstances, the mammary gland cells may either succumb to excess $\mathrm{Ca}^{2+}$, enter the apoptotic cascade, or remove the excess $\mathrm{Ca}^{2+}$ by some mechanism and survive. That mechanism to survive is the removal of excess $\mathrm{Ca}^{2+}$ through the RER-Golgi complex. Here, the true role of cargo proteins becomes apparent. The RER primarily produces cargo proteins that can bind and transport lots of $\mathrm{Ca}^{2+}$. The major milk protein is casein, but many other proteins are present in milk. The key role of the RER-Golgi complex system lies in the removal of excess $\mathrm{Ca}^{2+}$ from the cytoplasm with the help of the $\mathrm{Ca}^{2+}$-binding cargo proteins. A huge concentration of $\mathrm{Ca}^{2+}$ in milk is an important evolution.

\subsubsection{Secretion of Farnesol and FLS: Arguments in Favor of the "Hormone" Status of Farnesol}

The previous paragraph argues that cells with abundant RER are cells with a major $\mathrm{Ca}^{2+}$ homeostasis problem. Thapsigargin-sensitive SERCA pumps [31] are present in the membranes of RER and SER. Interestingly, special $\mathrm{Ca}^{2+}$-ATPases, with binding sites for regulatory proteins, also exist on the Golgi complexes. But, they have not yet been tested for their affinities for endogenous sesquiterpenoid ligands [24].

Endocrinological research in insects provided a foundation to the hypothesis that farnesol and FLS play a role in the functioning of Golgi. In 1970, De Loof and Lagasse were the first to mention such a role for juvenile hormone/farnesol, stemming from their pioneering research on the mode of action of juvenile hormone [7] (Figure 5). They observed that the fat body enormously hypertrophied in adult Colorado potato beetles (Leptinotarsa decemlineata), when preparing to enter diapause stage. Diapause is induced by the inactivation of corpora allata (CA), at that time the only known site for synthesis of juvenile hormone. Keeping the beetles in short-day conditions 
(less than $12 \mathrm{~h}$ light per day) inactivates the CA. The CA can also be surgically removed from the beetles reared under long-day conditions (more than $12 \mathrm{~h}$ light per day). Also, the latter treatment led to the fat body being hypertrophied. When such JH-deficient beetles were injected with synthetic $\mathrm{JH}$, the diapause induction was inhibited. As a control, De Loof and Lagasse [7] surgically removed the ovaries of adult females reared under long-day conditions, a surgery that also results in fat body hypertrophy.

Figure 5 compares the ultrastructure of fat bodies in both the conditions, indicating the presence of $\mathrm{JH}$ in ovariectomized females, and the absence of $\mathrm{JH}$ in short-day, pre-diapause stage adult females. The differences were drastic and pointed to the malfunctioning of the Golgi complex. In the absence of JH, the small secretory vesicles, produced by the Golgi body, fused with one another, resulting in numerous large protein bodies (PB) inside the cells (Figure 5D). These protein bodies have been shown to contain lysosomal enzymes [32]. Administration of synthetic JH or implantation of active CA prevented the dysfunction of the Golgi complex. This comparison also revealed changes not only in the secretory activity of the Golgi complex but also in lipid metabolism, glycogen accumulation, the structures of nucleus and cytoskeleton, as well as protein synthesis (abundance of the RER). In addition, in the absence of $\mathrm{JH}$, animals change behavior: they burrow into the soil to pupate (larvae) or hibernate (adults), and become immobile. Thus, $\mathrm{JH} /$ farnesol is a master hormone that concurrently influences numerous major physiological as well as some behavioral activities.

For a long time, the mechanism of farnesol/JH to execute such control over several processes was unknown. Now, we start to understand this mechanism-through the integrated $\mathrm{Ca}^{2+}$ homeostasis system as its main target system.

Clearing the body of farnesol/JH not only occurred in pre-diapausing adults but also in larvae preparing for complete metamorphosis. The changes induced in their fat body cells were similar to those induced in adults entering a pre-diapause stage. This led to the conclusion that some of the changes in the physiology of metamorphosing animals are "diapause-like" [8]. 


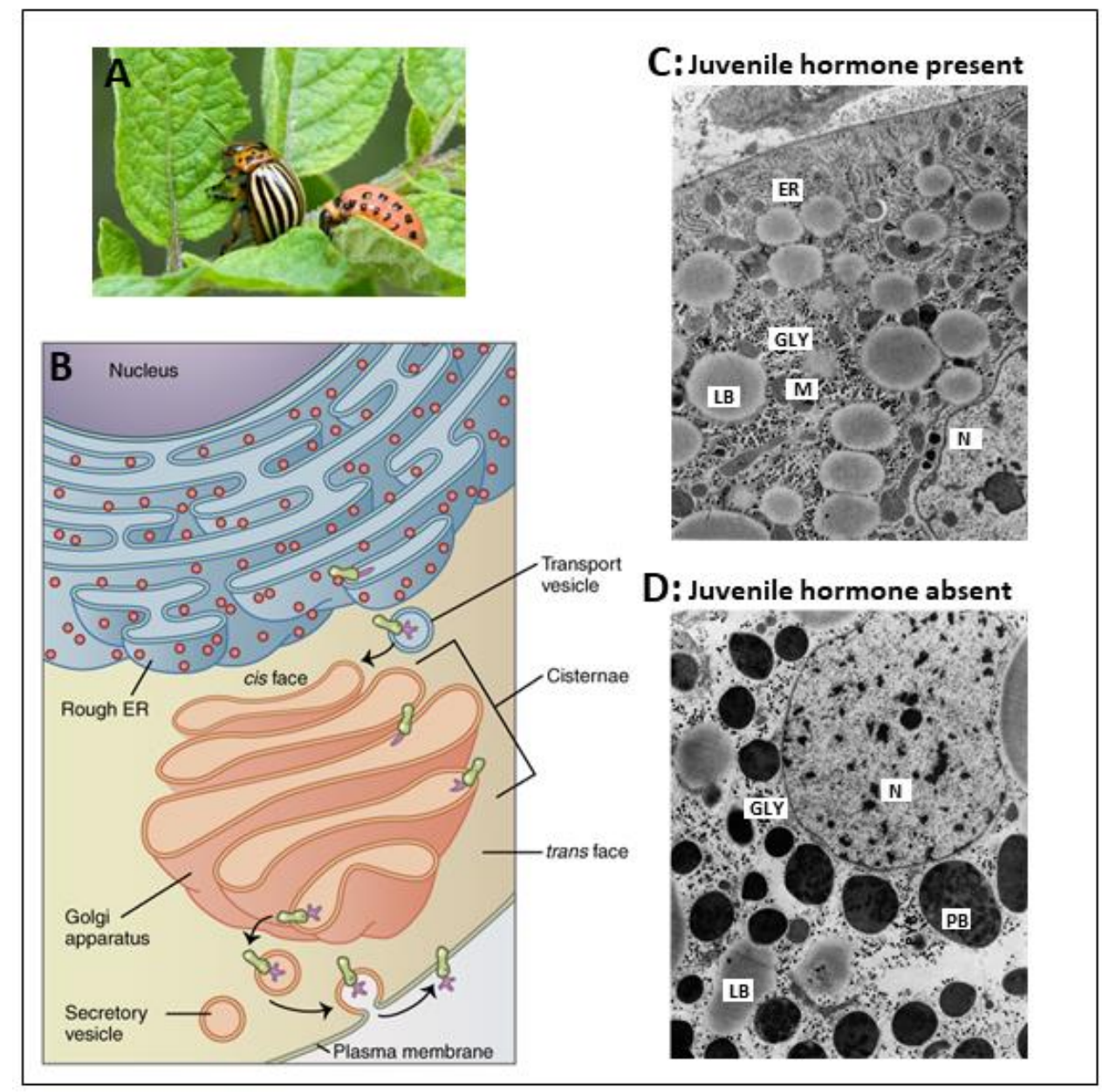

Figure 5 Effects of juvenile hormone in female Colorado potato beetles. A. Larva and adult female Colorado potato beetles (Google images). B. Schematic representation of the secretory system displays the involvement of the rough ER and the Golgi apparatus in transporting the cargo proteins to the exterior of the cell [30]. C and D. Comparison of the ultrastructure of fat body cells of two adult Colorado potato beetle females that were forced to undergo hypertrophy of the whole fat body. In control (C), the beetle was reared under the long-day conditions, activating the CA to produce $\mathrm{JH}$. In addition, the beetle was ovariectomized. Thus, the hypertrophy happened in the presence of $\mathrm{JH}$. In the second condition (D), the beetle was reared under short-day conditions, inactivating the CA (no JH production). Thus, the hypertrophy happened in the absence of $\mathrm{JH}$. The comparison shows that in the absence of $\mathrm{JH}$, there is an enormous accumulation of protein bodies (PB) that contain storage or diapause proteins, resulting from abnormal processing of secretory vesicles of the Golgi apparatus. The secretory vesicles released from the Golgi complex in long-day conditions are small, and neither fuse with one another nor accumulate in the cytoplasm. The opposite happens in the absence of JH. The newly formed secretory vesicles are small, but they fuse with one another and form large protein bodies that accumulate in the cytoplasm (Modified from [32]). ER - Endoplasmic Reticulum; GLY - glycogen; M - mitochondrion, $\mathrm{N}$ - nucleus; LB - lipid body; PB - protein body. All Open Access. Additional information in [7]. 


\subsubsection{Ancient Data Spark the Idea of Polarized Transport of Farnesol/JH}

Over half a century ago, Carroll Williams at Harvard observed that the abdomens of only male adult cecropia moths were a rich source of a compound with potent JH activity. This finding enabled the extraction of a sufficient amount of this compound to identify JH I. Moreover, it was found that JH was unevenly distributed in the abdomen; however, it was concentrated in the male accessory glands (MAG), the functional equivalent of mammalian prostate. Owing to the prevalent view at that time that the insect CA was the only site of JH synthesis, it was assumed that JH in the MAGs was originally synthesized in the CA and transported to MAGs, where it could be stored [33]. However, this "repository of $\mathrm{JH}$ explanation" was labile, as no JH activity was found in the hemolymph during metamorphosis, when JH accumulates in the MAGs. Years later, Borovsky et al. $[34,35]$ reinvestigated the MAGs in adult mosquitoes and reported that both MAGs and ovaries synthesize JH. This finding was not readily accepted by the international JH community and it took another 20 years before Paroulek and Sláma [36] reinvestigated JH synthesis in the original insect model that was used for identifying JH I, namely, $H$. cecropia. They concluded unambiguously that $\mathrm{JH}$ I was synthesized by MAGs and not transported from the CA to MAGs during metamorphosis.

However, their finding led to another issue-why is $\mathrm{JH}$, which is massively synthesized in the MAGs, not secreted into the hemolymph, unlike JH of the CA that freely diffuses through the plasma membranes of the CA cells into the hemocoel-hemolymph? Thus, there existed a dilemma: is $\mathrm{JH}$, and by extension farnesol/FLS as well, secreted by free diffusion in and out the CA, or is it subject to unidirectional polarized transport just as in the MAGs?

\subsubsection{Unidirectional Polarized Transport of JH Is Technically Possible}

It appears improbable that a small hydrophobic molecule such as farnesol/FLS would not freely diffuse out the site of synthesis, i.e., CA, and bind to lipoproteins present in the hemolymph. It is not clear whether it ends up in the plasma membrane of the CA cells by simple diffusion in a watery intracellular environment or via polarized transport within the CA cells. After reviewing the available literature on the ultrastructure of the corpus cardiacum and corpus allatum, it was found that a study [37] reported that, although the CA cells of Acheta domesticus are not known to secrete proteins, they contain an active Golgi system that secretes as yet unidentified protein(s). These data are in line with the findings of a study [36] on the polarized transport of JH I bound to secretory proteins in the MAGs. It is, therefore, possible that secretory protein-bound JH is also transported to the plasma membrane of CA cells. This is reminiscent of the manner the steroid hormone ecdysone, also a hydrophobic molecule exits its site of synthesis. Moreover, Yamanaka et al. [38] reported that the trafficking of steroids out of the endocrine cells does not always occur through a simple diffusion mechanism (which is the common notion); instead, it may involve a regulated vesicle-mediated release.

\section{Markers of Alzheimer's Disease}

When dysfunction of the Golgi apparatus and other cell functions, similar to that reported in the Colorado beetle in the absence of $\mathrm{JH}$, occurs in human brain cells, it severely disturbs the release of vesicles in the presynaptic elements. As mentioned in $\S 6.4 .2$, the Golgi secretory vesicles contain lysosomal enzymes in the absence of farnesol/FSL [32]. To our knowledge, AD has 
not yet been studied from the perspective of being a remnant of an ancient mechanism of diapause/hibernation that lost its function during evolution. However, abnormal mitochondrial functioning, an efficient mechanism used by diapausing/hibernating animals to reduce metabolism, has been suggested as one of the possible inducers of Alzheimer's disease (AD) [3942]. It would be interesting to study whether the reported physiological hallmarks of insect metamorphosis and diapause/hibernation display similarities with the ones typical for AD?

This relatively simple question forces us to explicitly state that it is not the intention of this study to discuss the complexity of biological and medical aspects of $A D[2,43]$, as illustrated by the following figures: PubMed: Alzheimer's disease: 148,489 hits on August 26, 2019; Wikipedia: Alzheimer's disease: 296 references on August 26, 2019. We entrust the medical and clinical aspects to specialists in the domain. Several interesting insights into AD and other neurodegenerative diseases have emerged in the past two decades [43-60]. As biologists specialized in animal physiology and comparative endocrinology, we only focus on certain physiological aspects from a comparative invertebrate-vertebrate perspective, with a special interest in the possible roles of farnesol/FLS in AD. To date, the scarcity of hits in a PubMed search: Alzheimer AND farnesol yielded only 11 hits (August 26, 2019), made us the loners (in biblical terminology, "little Davids") with our ideas. Farnesol is still poorly studied [11], in particular with regard to $A D$, undeservedly, however, as argued in this review.

\subsection{Are Prominent Proteins in Alzheimer's Disease, Neurofibrillary Tangles, and Amyloid-Beta Plaques the Cause or the Result?}

In the past few decades the main focus of research on the biochemistry and cell physiology of aging and aging-related diseases, of which Alzheimer's disease is the most studied one, has been on abnormalities in brain-borne proteins, in particular on amyloid-beta $(A \beta)$ peptide deposits in extracellular plaques, intracellular neurofibrillary tangles of aggregated tau $[40,56]$ and on synaptic dysfunction and neuronal death $[59,60]$ (Figure 6). A plethora of other proteins/enzymes, RNAs, as well as lipids [61], epigenetics [61], and oxidative stress [62] also play a causative or peripheral role. At the cytoarchitectural level, neurofibrillary tangles and amyloid plaques are considered as relatively "early" markers of the disease, whereas massive apoptosis is a later marker.

According to a study [63], "neurofibrillary tangles (NFTs)" are aggregates of hyperphosphorylated tau protein that are most commonly known as a primary marker of AD. These have also been reported in numerous other diseases known as tauopathies. However, little is known about their exact relationship with different pathologies."

According to the same study [64], "Amyloids" are aggregates of proteins, and not of "amylum" or starch as it was originally thought. These are folded in a manner allowing several copies of the protein adhere together to form fibrils. Amyloids have been known to arise from several different proteins and polypeptides. In the human body, amyloids have been linked to the development of several diseases. A study reports the list of diseases in which amyloids and other proteins linked to (degenerative) brain diseases occur and may play a role [64]. 


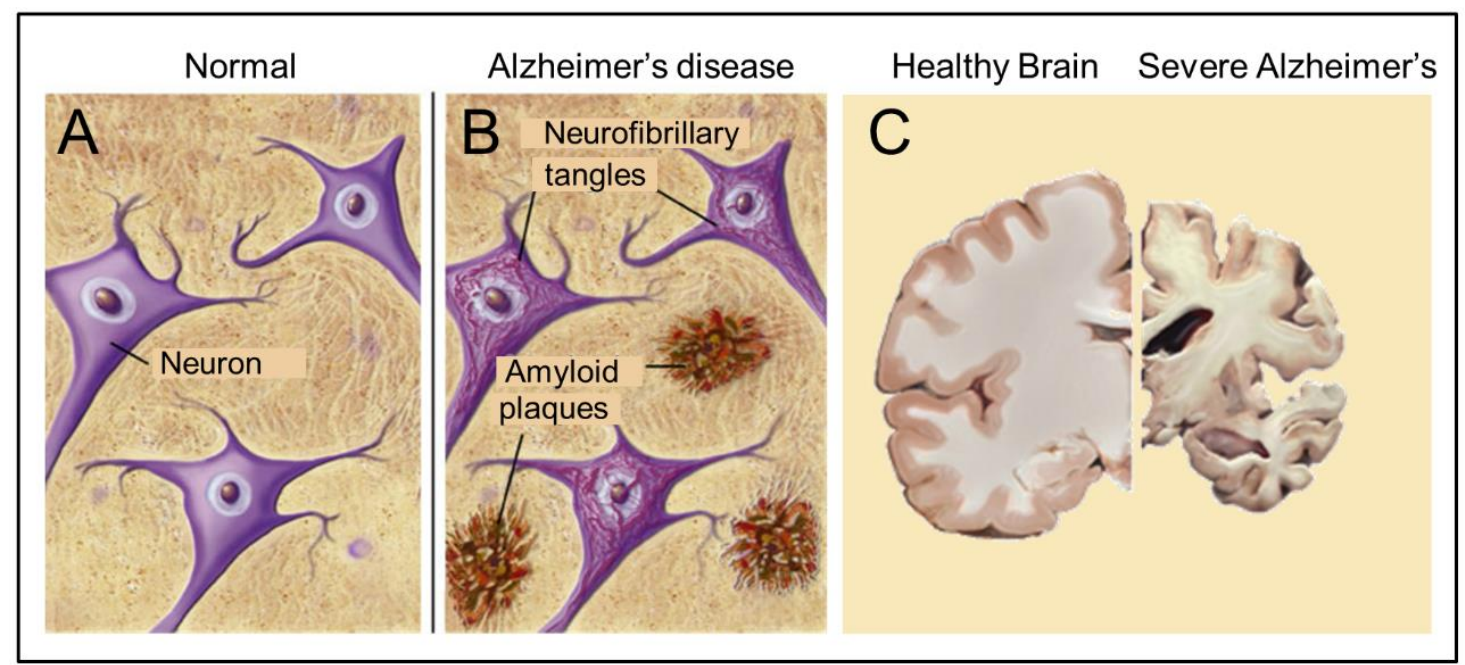

Figure 6 Major pathological hallmarks of $A D$ are amyloid plaques and neurofibrillary tangles (B) that are absent in healthy brain tissue (A). Massive apoptosis occurs in later stages of the development of $A D$ in the human brain (brain slices) (C). Sources: $\mathbf{A}$ and B: Google Images, BrightFocus Foundation (Alzheimer's disease: Amyloid Plaques and Neurofibrillary tangles). C: Wikimedia, from Elsevier Sci. Tech connect. The neural bas is of Alzheimer's disease. Posted by Caitlin Beddows, 2016. All figures could be openly accessed.

In the recent decade the awareness has increased that amyloid-beta and tau are a result of $A D$ rather than its cause [51]. In addition to biochemical causes of the disease, insufficient knowledge on the functioning of our cognitive memory system has remained a major hurdle. How the plasma membrane-cytoskeletal complex, the electrical phenomena, and other players act in a coordinated manner in this system remains largely a black box [65]. According to a study [40], Tau-mediated synthesis of neurofibrillary tangles in $A D$ brains shows a better correlation with cognitive impairment than $A \beta$ accumulation. Pathological tau alone is sufficient for eliciting frontotemporal dementia; however, it does not cause AD.

\subsection{Alzheimer's Disease and Cholesterol: The Fat Connection}

Figure 3 illustrates the dichotomy of the mevalonate pathway between insects and vertebrates/mammals. Insects do not have the gene coding for squalene synthase and thus cannot synthesize cholesterol. For insects, cholesterol is a vitamin that has to be ingested with the food, either as cholesterol (in carnivorous insects) or in the form of a compound which could further be converted to cholesterol in the insect's body, e.g., from ecdysteroids (in herbivores). In addition, insects do not accumulate high concentrations of cholesterol in their hemolymph. They have an open circulatory system, meaning they have a heart, but no arteries or veins. The changes typical to metamorphosis are attributed to the absence of farnesol/FLS and not the absence of the squalene-cholesterol step of the mevalonate pathway.

A current line of thought in $A D$ research is that some lipids, in particular, cholesterol, when present in high concentrations in blood, act as major risk factors for AD. This condition is known as "the fat connection" [66]. Cholesterol is known to affect $A \beta$ generation and toxicity. However, not 
all humans are equally sensitive. According to a study [67], the roles of total cholesterol, lowdensity lipoprotein cholesterol, high-density lipoprotein cholesterol, triglycerides, and apolipoprotein, or phosphoinositides and phosphatidic acid [64] are not clear for all genetic variants that are susceptible to $A D$ risk. Moreover, the use of statin-like drugs for the treatment of brain cholesterol loss in $A D$ is associated with variable results and may depend on variations in lipid profile in $A D$ and variable genetic backgrounds of patients $[68,69]$. According to another study [70], "cholesterol as a causative factor in Alzheimer's disease," is a debatable hypothesis.

One of the other intermediate steps in the biosynthesis of cholesterol is the synthesis of farnesylpyrophosphate. In addition to its role as an intermediate in the synthesis of squalene, farnesylpyrophosphate is used in prenylation. Prenylation is the covalent addition of a farnesyl or a geranylgeranyl group to particular proteins, e.g., small GTPases [71]. A functional link involving $\mathrm{Ca}^{2+}$ signaling exists between the prenylation of $\alpha$ and $\gamma \mathrm{G}$-proteins and GPCR signaling [11]. According to a study [72], isoprenoids and protein prenylation may be implicated in the pathogenesis and therapeutic intervention of AD. Hooff et al. [71] reported significantly elevated levels of farnesyl pyrophosphate (FPP) and geranylgeranyl pyrophosphate (GGPP) in human AD brain tissue, whereas cholesterol levels did not differ between AD and control samples. The same group also reported [73] that these brain isoprenoids were increased in aged mice.

It could be concluded from our searches in PubMed that the idea that farnesol itself might have a causal link to $A D$ induction, was never accepted by the students believing in "fat connection to $A D$." The research interests in the field of AD and of insect physiology with respect to functions of farnesol/FLS clearly do not overlap.

\section{Neurodegeneration}

\subsection{Apoptosis has a Causal Link with $\mathrm{Ca}^{2+}$ Homeostasis through Farnesol/FLS/JH}

Apoptosis prominently occurs in the brain in the later stages of $A D[46,74]$. Our interest in $A D$ was triggered by the fact that apoptosis, linked to $\mathrm{Ca}^{2+}$-homeostasis, is the same process that is responsible for the lysis of several tissues during metamorphosis of all insect species undergoing complete metamorphosis. In contrast to $A D$ in humans, the molecular primordial inducer of insect apoptosis/programmed cell death is known; it is a decrease to the zero titer of all endogenous sesquiterpenoid compounds with "juvenile hormone" activity. The chemical nature of insect JHs, farnesol and its JH-esters, has been known for half a century.

Vertebrates, including humans, do not produce such esters of farnesol. However, like all eukaryotes, they do synthesize farnesol (Figure 2). As farnesol is not (yet) known as a hormone in vertebrates, and in contrast to insects, there is no bioassay to detect such activity in vertebrates, the prevailing idea was, and still is, that vertebrates do not have-and do not need-a juvenile hormone to prevent aging [17]. However, farnesol itself, irrespective of its extraction from insects, plants, or mammalian tissues, has moderate JH activity in typical insect bioassays for juvenile hormone. It was suggested in 2015 that vertebrates use farnesol (derivatives) as a juvenilizing factor, probably not as a hormone but as an "inbrome," thereby acting as a compound that acts from within the membrane [17], the mode of action of which, however, remains to be discovered. The authors were then unaware that the receptor for farnesol had already been described in 1999 by a group $[21,22]$ that reported that it is a potent endogenous blocker of particular types of 
voltage-gated $\mathrm{Ca}^{2+}$-channels. Meanwhile, farnesol has gradually become a better-known element of the signaling pathways in both animals and plants $[6,11]$. This awareness triggered the question, whether a malfunctioning farnesol synthesis system, namely, the mevalonate biosynthetic pathway, forms the basis of cellular degeneration in both metamorphic insect cells and in $A D$ and whether we are looking at the very same cell physiological mechanism. If this is indeed the case, does this open new avenues toward preventing and delaying the disease? This necessitates a different way of thinking. In particular, given that the principles of cell biology/physiology are universal and thus very similar in both invertebrates and vertebrates, one should accept that for studying some aspects of cell physiology, selected invertebrate models are better than vertebrate models.

\subsection{Alzheimer's Disease: Has the Possible Role of Endogenous Sesquiterpenoids been Overlooked?}

We are convinced that the role of endogenous sesquiterpenoids has been overlooked. We argue that $A D$ could rather be the result of a primordial malfunctioning lipid-based mechanism than a causative dysfunctional primordial protein(s). The class of lipids could be the endogenous farnesol-like sesquiterpenoids (FLS), in particular farnesol and possibly (some of) its derivatives.

We postulate the following mechanism. When the mevalonate pathway functions suboptimally, the concentration of intracellular (cytoplasmic) free $\mathrm{Ca}^{2+}$ starts rising due to a weakened $\mathrm{Ca}^{2+}$ extrusion capacity of cells for which farnesol is an agonist. As cited before [21, 22], farnesol is a potent blocker of $\mathrm{N}$-type $\mathrm{Ca}^{2+}$ channels. In addition, based on the fact that the sesquiterpenoid thapsigargin blocks $\mathrm{Ca}^{2+}$ transport by the SERCA pump, it could be deduced that lowering farnesol under a critical threshold may first result in increased Golgicrine $\mathrm{Ca}^{2+}$ removal activity followed by Golgicrine arrest. Normal synaptic functioning will be impeded (Fig ure 7). Synaptic dysfunction is one of the characteristics of $A D$ [60]. Finally, apoptosis is induced. Other cellular activities that could be influenced have been shown by experiments on the Colorado potato beetle (Fig ure 5) [8], which confirmed that farnesol/FLS is a multifunctional signaling molecule.

Figure 7, borrowed from Google Images, specifically focuses on axonal transport. (A) Large secretory proteins (pre-propeptides) are converted into smaller propeptides in the rough endoplasmic reticulum (RER). The propeptides and enzymes are packaged into vesicles that are transported to the Golgi apparatus, modified, and packaged into vesicles. The vesicles get attached to microtubules and are carried to the terminals by fast axonal transport. The propeptides are cleaved to produce smaller peptide transmitters in the terminal. Small molecule neurotrans mitters are synthesized in the neuronal terminal and packaged into vesicles. The peptides and neurotransmitters are released into the synaptic cleft by exocytosis. Surplus membrane elements in the terminal are carried back to the cell body by retrograde transport. The retrieved vesicular membrane is degraded or recycled. (B) A model showing how kinesin (a microtubule-associated ATPase) can move an organelle along a microtubule. This figure is listed in Google Images, without specific information on the authors, only general information. From: What-when-how; In Depth Tutorials and Information; Histology of the Nervous System (The Neuron) Part 1, The Neuron Figure 6-2. For lack of information about the author of the figure, Open Access is assumed. With thanks to the anonymous author(s). 


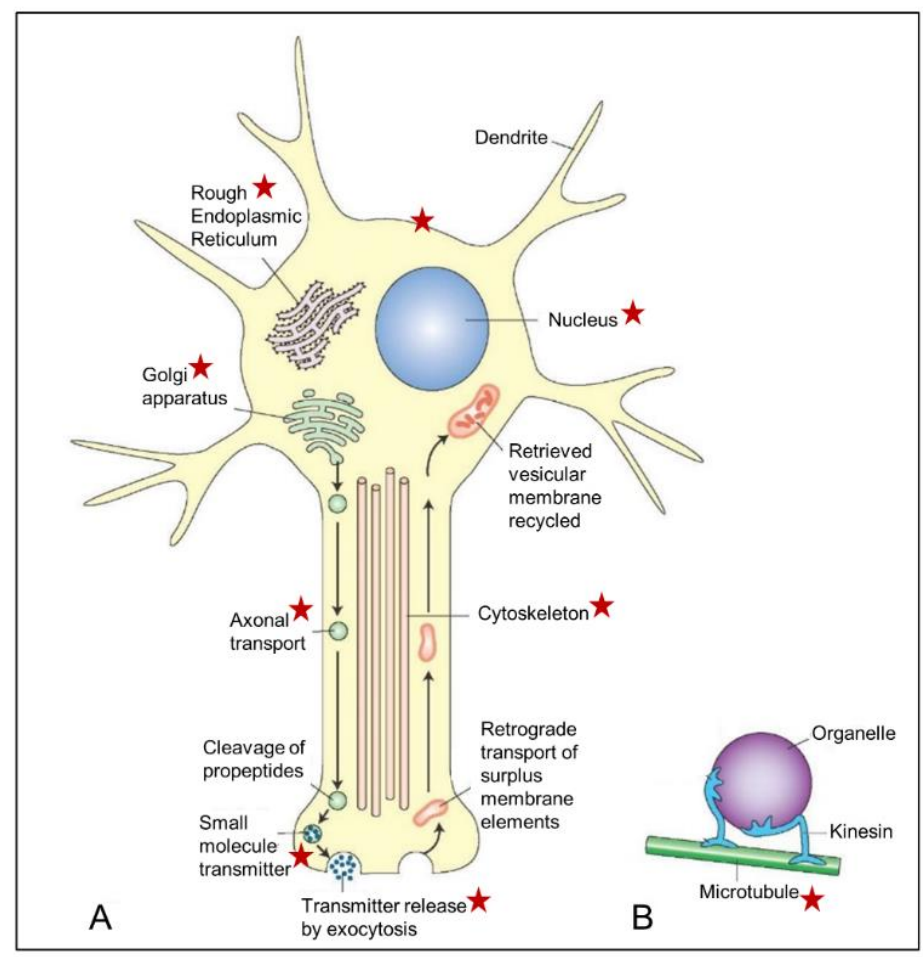

Figure 7 Schematic representation of a neuron illustrating the major cellular sites and cell organelles under the influence of endogenous farnesol-like sesquiterpenoids, as indicated by red asterisks. This list is not exhaustive (e.g., mitochondria, although known to be a target of farnesol/FLS [8], are not included in this figure). The functional relation between farnesol/FLS and the $\mathrm{Ca}^{2+}$ homeostasis system with its numerous factors explains the several target sites. The figure is combinatorial: the asterisks represent data from different experimental models. The basic idea is also valid for other cell types, in particular for those with an active RER-Golgi system.

\section{Which Brain Neuropeptide(s) or Neurotransmitter Control Farnesol/FLS Synthesis?}

So far, we focused on the direct downstream effects of farnesol/FLS/JH. However, the possibility of a higher-order cause for the dysfunctioning of the mevalonate pathway exists. It is likely that in animals the pathway is controlled by a neuropeptidergic system.

In insects, this area has been thoroughly investigated; however, a mechanism that applies to all holometabolic species has not yet been found. Depending upon the species, the JH biosynthesis by the CA could be controlled in several ways. The best documented neuropeptides controlling JH biosynthesis are allatostatins and allatotropins. More recently, it was hypothesized that perhaps the total absence of short NeuroPeptide F (sNPF, not to be confused with regular NPY/NPFs [75, 76]; De Loof and Schoofs, in preparation) could be a candidate, given its wide distribution across bilaterians. The first SNPF was isolated from brain extracts of the Colorado potato beetle [77]. Potent stimulating effects of SNPF on reproduction in adult female locusts were described [78]. Later, it was reported that sNPF was totally absent in diapausing Colorado potato beetles [79], and that sNPF was absent in the late larval stage; however, it was present in adult tsetse flies [80]. According to a study [76], the short NPF system appears to have been lost or evolved into the prolactin-releasing peptide signaling system during chordate evolution. 


\section{Final Major Difference: In Insects, Some Apoptotic Tissues Regenerate Anew, but the Brain of Alzheimer's Patients does not: A Difference in Steroid Hormones?}

During metamorphosis, tissues undergoing programmed cell death completely disappear and are replaced by newly formed adult tissues. These develop from preexisting stem cells. Apparently, these stem cells do not suffer from the absence of farnesol/FLS/JH in their early growth phase. Either their $\mathrm{Ca}^{2+}$ homeostasis system is not sensitive to an inactive mevalonate pathway, or they are protected by an as yet unknown factor. Such protection may, perhaps, be achieved by the presence of high titers of vitamin $D_{1}$, a name which has recently been given by Karel Sláma [81] to the ecdysteroid 20-OH ecdysone (De Loof and Schoofs, in preparation), formerly better known as the "molting hormone" of insects, the functional counterpart of estrogens, the female sex hormones of vertebrates [82]. This ecdysteroid functions as a water-soluble anabolic steroid both in insects and some vertebrates, e.g., quails and humans. It is present in high concentrations in some plants, e.g., in Leuzea. It is legally used for some applications in humans, in particular for enhancing physical performance. How such "insect steroid" that is not biosynthesized in vertebrates, can nonetheless stimulate growth in humans is only partially understood [83-86].

\section{Conclusions}

- To date, the proteins amyloid-beta $(A \beta)$ and tau, major hallmarks of $A D$, a re being actively considered as the result than the cause of $A D$.

- A dysfunctional mevalonate biosynthetic pathway may be an early trigger of $A D$ (this study).

- This pathway is omnipresent in ALL eukaryotes, including human brain cells.

- The pathway's essence is the synthesis of farnesyl(PP) and farnesol, "the noble unknown in cell physiology."

- Farnesol and, where present, its esters (FLS) with more potent juvenile hormone (JH)/antiaging activity than farnesol itself, are multifunctional sesquiterpenoids, not proteins. Hence, they are as such not encoded by single genes, and thus other methods than the ones used in classical molecular biology, are required to uncover their molecular mode of action.

- The major function of farnesol/FLS is to keep - at high titer-free cytoplasmic $\left[\mathrm{Ca}^{2+}\right]$ low. Acting (partially) through the complex $\mathrm{Ca}^{2+}$ homeostasis system explains their multifunctionality.

- Farnesyl(PP) also acts as the intermediate for the synthesis of other molecules of the pathway, e.g., squalene and cholesterol (only in vertebrates).

- Because farnesol/FLS are highly hydrophobic, they are very poorly soluble in water. They have instead a high affinity for all types of cellular membranes. They readily diffuse through the connected intracellular membrane system, which is present in all cells of the body.

- Upon diffusion, farnesol/FLS meets several types of membrane proteins, with a large variety of (enzymatic) functions. Some intramembrane macromolecules have a binding pocket for endogenous sesquiterpenoids and can act as receptors.

- Several hallmarks of AD closely resemble those of insect tissues during complete metamorphosis or during diapause/hibernation, undergoing massive programmed cell death/apoptosis.

- Such metamorphosis is initiated by a decrease in the titer to zero of farnesol/juvenile hormone. 


\section{Discussion}

At first confrontation, the idea that a single molecule, that is universally present in all eukaryotes may be a major cause for inducing Alzheimer's disease may meet with great skepticism. In particular, when this molecule is suggested to be the "noble unknown farnesol" [6], and even more, when not its presence but the decrease of its titer to very low values may be the culprit. A major reason for such skepticism might be that $A D$ is so multifaceted that a plethora of factors may be involved. Figure 4 in the present study illustrates that this not necessarily the case, to the contrary, it is very well possible. Furthermore, it is believed that if farnesol would be important, its crucial role would have manifested itself long ago in experimental approaches, instead of remaining relatively unknown for so long [6]. Another reason might be that several relatively recent, novel concepts in cell biology have not yet reached the status of "common knowledge".-The major ones, which by now have been experimentally validated are: "inbrome" [17], Calcitox [26], the mevalonate pathway as a major system for controlling $\mathrm{Ca}^{2+}$ homeostasis by keeping $\left[\mathrm{Ca}^{2+}\right]$ i low [20], Golgicrine activity (De Loof and Schoofs, in preparation), the Golgi system requiring farnesol/FLS/JH for its protein secretory activity $[6,36]$, and "unidirectional transepithelial transport" of farnesol/FLS (De Loof and Schoofs, in preparation). Only some mechanisms could be discussed if a suitable vocabulary would be available, which was not the case. That continues to be a problem in cell physiology, and that is the reason why this new terminology has been introduced.

In our opinion, it is possible that instead of having a modest role in cell biology and endocrinology, farnesol could be a major animal hormone or inbrome that is synthesized at multiple sites in the body (liver, pancreas, gut, brain, and other organs). Such universality may perhaps explain why Gilbert and Schneiderman [87], believing that the "juvenile hormone of insects" might be a steroid, discovered juvenile hormone-like activity in the extracts of the human adrenal cortex, though they did not identify the chemical nature of the responsible factor(s). It was not before 1999, when data were published on the concentration of trans,trans-farnesol (= the active isomer) in the human brain (see $\S 4)[21,22]$ that the presence and identity of farnesol-like sesquiterpenoids in the human brain became irrefutably proven.

We understand that some researchers will have doubts and objections to our approach and may find it too simplistic. Indeed, our hypothesis proposes that a cause of the early induction of $A D$ might be the dysfunctional "Golgicrine" activity, resulting in drastic secondary effects on (cargo) protein-, $\mathrm{Ca}^{2+}{ }^{2}$, and farnesol secretion. This view could be maintained because our study in insect development/physiology/endocrinology, more specifically on farnesol and on its even more potent juvenile hormone esters, has experimentally validated that farnesol/FLS/JH could concurrently control almost all basic cell physiological functions: protein, lipid, glycogen, mitochondrial multiplication, inhibition of apoptosis, conformation of the cytoskeleton, epigenetic control of gene expression (important in AD [58]), etc. The role of farnesol/FLS in epigenetic control of gene expression has been convincingly validated through the study of the transition from the solitarious to the gregarious phase in locusts [88]. How can farnesol do so? By playing the role of the most important key regulator of $\mathrm{Ca}^{2+}$ homeostasis. In theory, what is possible in insects should be possible in humans as well. Key signaling pathways that came into existence in early evolutionary history have a high degree of perfection, and they are remarkably well conserved during millions or even billions of years. 
High farnesol/JH concentrations, which maintain the "status quo" in insect development, thus the larval stage, apparently do so by inhibiting $\mathrm{Ca}^{2+}$ influx into the cells, thereby preventing $\mathrm{Ca}^{2+}$ induced apoptosis [42]. When the farnesol/JH titer drops, from a certain (not yet determined) threshold on, excess $\mathrm{Ca}^{2+}$ enters the cells. If the $\mathrm{Ca}^{2+}$-ATPase pumps or the temporary $\mathrm{Ca}^{2+}$ storage in the SER [26] cannot handle the toxic situation, the RER-Golgi complex is invoked to remove the excess $\mathrm{Ca}^{2+}$ to attain $\mathrm{Ca}^{2+}$-homeostasis. Apparently, the Golgi secretory system requires farnesol for the unidirectional export out of the cell. This may involve the cytoskeleton system. When this system also fails, the cell collapses, and apoptosis is induced. Brain cells in which this happens do not survive. Another mechanism is that the production of secretion vesicle containing neurotransmitters stops functioning. In the absence of stimulation, nerve cells enter a state of diapause (like in insects) or die.

In retrospect, the almost complete absence of interest of cell biologists and animal endocrinologists in farnesol and its synthetic pathway, stems from the fact that almost nobody considered the possibility that farnesol could have a role in cell physiology, in addition to serving as an intermediate in the biosynthesis of cholesterol in vertebrates. Furthermore, in vertebrates, there is no developmental stage in which the mevalonate pathway comes to a complete standstill. Hence, no bioassays for investigating the role of farnesol in vertebrates have been developed.

The literature on the effects of farnesol in the medical context is rather limited. It is mainly related to antioxidant effects, quorum sensing, antifungal effects, and cancer (e.g., positive effects on treating pancreatic cancer [89]). In insects, farnesol has been better studied because it was known that it might serve as the precursor of the master hormone "juvenile hormone."

We agree with the study of Popugaeva et al. [90] that reported that it might be a defendable strategy to restore calcium homeostasis to treat/prevent/attenuate the early induction steps of AD. We believe that some farnesol derivatives could be involved. All-trans-farnesol (= the most potent isomer in insect bioassays) itself is commercially available in the market in large quantities and relatively cheaply. In addition, approximately 4,000 synthetic JH-analogs have been synthesized in the past half century, not in a medical context but for the purpose of plant protection [91, 92]. The goal was to develop insect growth regulators as insecticides that were almost not toxic to vertebrates. Researchers may not have thought to test them for preventing and treating neurodegenerative diseases, because in the "old days" that was not an issue. Recently, a search for novel compounds in plants revealed several sesquiterpenoids with anti-Alzheimer's disease activity in extracts of rhizomes and roots from the perennial herbal plant Nardostachys chinensis Batal (Valerianaceae) [93].

If $A D$ researchers might decide to (partially) (re)orient their interests away from the proteins tau, amyloids, secretases, and presinilins to farnesol/FLS/mevalonate pathway, they should be aware of the fact that this would imply a very different experimental approach. From mostly working with water-soluble compounds and the methods of molecular biology, to working with hydrophobic molecules that stick to everything and have a high affinity for me mbranes will require considerable experimental adjustments [94].

\section{Acknowledgements}

We acknowledge the KU Leuven Research Foundation and the FWO (grant number G0C0618N to LS) for financial support. Our sincere thanks to all authors of the figures used in this paper which 
have been made available through Open Access sources, to Marijke Christiaens for help with the layout of the figures, and to Michael Gaffney for language help.

\section{Author contributions}

ADL and LS jointly conceived and wrote the paper.

\section{Competing interests}

The authors declare no competing financial interest.

\section{References}

1. Noble W, Hanger D, Gallo J-M. Transgenic mouse models of tauopathy in drug discovery. CNS Neurol Disord Drug Targets.. 2010; 9: 403-428.

2. Wikipedia: Alzheimer's disease. 2019.2 Available from: http://en.wikipedia.org/wiki/Alzheimer's disease.

3. Bouleau S, Tricoire H. Drosophila models of Alzheimer's disease: Advances, limits, and perspectives. J Alzheimers Dis. 2015; 45: 1015-1038.

4. Mclnnes J, Wierda K, Snellinx A, Bounti L, Wang Y-C, Stancu I-C, et al. Synaptogyrin-3 mediates presynaptic dysfunction induced by Tau. Neuron. 2018; 97: 823-835. e828.

5. Griffin EF, Caldwell KA, Caldwell GA. Genetic and pharmacological discovery for Alzheimer's disease using Caenorhabditis elegans. ACS Chem Neurosci. 2017; 8: 2596-2606.

6. De Loof A, Schoofs L. Mode of action of farnesol, the 'noble unknown' in particular in $\mathrm{Ca}(2+)$ homeostasis, and its juvenile hormone-esters in evolutionary retrospect. Front Neurosci. 2019; 13: 141.

7. De Loof A, Lagasse A. Juvenile hormone and the ultrastructural properties of the fat body of the adult Colora do beetle, Leptinotarsa decemlineata Say. Z Zellforsch Mikrosk Anat. 1970; 106: 439-450.

8. De Loof A. Diapause phenomena in non-diapausing last instar larvae, pupae, and pharate adults of the Colorado beetle. J Insect Physiol. 1972; 18: 1039-1047.

9. Wikipedia: Vachellia. 2019. Available from: http://en.wikipedia.org/wiki/Vachellia.

10. Wikipedia: Farnesol. 2019. Available from: http://en.wikipedia.org/wiki/Farnesol.

11. De Loof A, Schoofs L. Flip-Flopping retinal in microbial rhodopsins as a template for a farnesyl/prenyl Flip-Flop model in Eukaryote GPCRs. Front Neurosci. 2019; 13: 465.

12. Bezerra D, Araújo I, da Cunha Lins G, Bandeira P, Barbosa R, Melo HC, et al. Toxicological and pharmacologic effects of farnesol $(\mathrm{C} 15 \mathrm{H} 26 \mathrm{O})$ : A descriptive systematic review. Food Chem Toxicol. 2019; 129: 169-200.

13. Wikipedia: Sesquiterpene. 2019. Available at: http://en.wikipedia.org/wiki/Sesquiterpene.

14. Wikipedia: Calcium channel. 2019. Available from: http://en.wikipedia.org/wiki/Calcium Channel.

15. Schmialek P. Die Identifizierung zweier im Tenebrio kot und in Hefe vorkommender Substanzen mit Juvenilhormonwirkung. Z Naturforsch B. 1961; 16: 461-464.

16. Karlson P, Schmialek P. Nachweis der Exkretion von Juvenilhormon. Z Naturforsch B. 1959; 14 : 821. 
17. De Loof A, Marchal E, Rivera-Perez C, Noriega FG, Schoofs L. Farnesol-like endogenous sesquiterpenoids in vertebrates: the probable but overlooked functional "inbrome" anti-aging counterpart of juvenile hormone of insects? Front Endocrinol. 2015; 5: 222.

18. Wikipedia: Tenebrio.2019. Available from: http://en.wikipedia.org/wiki/Tenebrio.

19. Bellés X, Martín D, Piulachs MD. The mevalonate pathway and the synthesis of juvenile hormone in insects. Annu Rev Entomol. 2005; 50: 181-199.

20. De Loof A, De Haes W, Janssen T, Schoofs $L$. The essence of insect metamorphosis and aging: electrical rewiring of cells driven by the principles of juvenile hormone-dependent $\mathrm{Ca}^{2+}$ homeostasis. Gen Comp Endocrinol. 2014; 199: 70-85.

21. Roullet J-B, Spaetgens RL, Burlingame T, Feng Z-P, Zamponi GW. Modulation of neuronal voltage-gated calcium channels by farnesol. J Biol Chem. 1999; 274: 25439-25446.

22. Luft UC, Bychkov R, Gollasch M, Gross V, Roullet JB, McCarron DA, et al. Farnesol blocks the Ltype Ca2+ channel by targeting the $\alpha 1 C$ subunit. Arterioscler Thromb Vasc Biol. 1999; 19: 959966.

23. Thastrup O, Cullen PJ, Drøbak B, Hanley MR, Dawson AP. Thapsigargin, a tumor promoter, discharges intracellular $\mathrm{Ca} 2+$ stores by specific inhibition of the endoplasmic reticulum $\mathrm{Ca} 2$ (+)-ATPase. P Natl Acad Sci USA. 1990; 87: 2466-2470.

24. Vandecaetsbeek I, Vangheluwe $P$, Raeymaekers L, Wuytack F, Vanoevelen J. The Ca2+ pumps of the endoplasmic reticulum and Golgi apparatus. Cold Spring Harb Perspect Biol. 2011; 3: a004184.

25. Orrenius S, Zhivotovsky B, Nicotera P. Regulation of cell death: The calcium-apoptosis link Nat Rev Cell Biol. 2003; 10: 552-565.

26. De Loof A. Calcitox-aging counterbalanced by endogenous farnesol-like sesquiterpenoids: An undervalued evolutionarily ancient key signaling pathway. Commun Integr Biol. 2017; 10: e1341024.

27. Prossnitz ER, Arterburn JB, Sklar LA. GPR30: AG protein-coupled receptor for estrogen. Mol Cell Endocrinol. 2007; 265: 138-142.

28. Wikipedia: Apoptosis. 2019. Available from: http://en.wikipedia.org/wiki/Apoptosis.

29. Wikipedia: Endoplasmic reticulum. $2019 . \quad$ Available from: http://en.wikipedia.org/wiki/Endoplasmic reticulum.

30. Wikipedia: Golgi apparatus. 2019. Available from: http://en.wikipedia.org/wiki/Golgi apparatus.

31. Inesi G, Sagara Y. Thapsigargin, a high affinity and global inhibitor of intracellular Ca2+ transport ATPases. Arch Biochem Biophys. 1992; 298: 313-317.

32. De Loof A. Juvenile Hormone-dependent structural and functional changes in the ovaries, the fat body and the male reproductive accessory glands of the Colorado potato beetle (Leptinotarsa decemlineata Say). Aggregaatsthesis. 1972.

33. Shirk P, Dahm K, Roller $\mathrm{H}$. The accessory sex glands as the repository for juvenile hormone in male cecropia moths. Z Naturforsch C. 1976; 31: 199-200.

34. Borovsky D, Carlson D, Hancock R, Rembold H, van Handel E. De novo biosynthesis of juvenile hormone III and I by the accessory glands of the male mosquito. Insect Biochem Mol Biol. 1994; 24: 437-444.

35. Borovsky D, Carlson DA, Ujváry I, Prestwich GD. Biosynthesis of (10R)-juvenile hormone III from farnesoic acid by Aedes aegypti ovary. Arch Insect Biochem Physiol. 1994; 27: 11-25. 
36. Paroulek M, Sláma K. Production of the sesquiterpenoid juvenile hormone (JH-I), and of vitamin $\mathrm{E}$ in the accessory sexual (colleterial) glands of adult male moths, Hyalophora cecropia (Linnaeus, 1758),(Lepidoptera: Saturniidae). Life Exc Biol. 2014; 2: 102-124.

37. Bradley JT, Edwards JS. Ultrastructure of the corpus cardiacum and corpus allatum of the house cricket Acheta domesticus. Cell Tissue Res. 1979; 198: 201-208.

38. Yamanaka N, Marqués G, O'Connor MB. Vesicle-mediated steroid hormone secretion in Drosophila melanogaster. Cell. 2015; 163: 907-919.

39. Cabezas-Opazo FA, Vergara-Pulgar K, Pérez MJ, Jara C, Osorio-Fuentealba C, Quintanilla RA. Mitochondrial dysfunction contributes to the pathogenesis of Alzheimer's disease. Oxid Med Cell Longev. 2015; 2015.

40. Jeong S. Molecular and cellular basis of neurodegeneration in Alzheimer's disease. Mol Cells. 2017; 40: 613.

41. Albensi BC. Dysfunction of mitochondria: Implications for Alzheimer's disease. Int Rev Neurobiol. 2019; 145: 13-27.

42. Dai J, Gilbert LI. Juvenile hormone prevents the onset of programmed cell death in the prothoracic glands of Manduca sexta. Gen Comp Endocrinol. 1998; 109: 155-165.

43. Sala Frigerio C, Wolfs L, Fattorelli N, Thrupp N, Voytyuk I, Schmidt I, et al. The major risk factors for Alzheimer's disease: age, sex, and genes modulate the microglia response to $A \beta$ plaques. Cell Rep. 2019; 27: 1293-1306.

44. Van Broeck B, Van Broeckhoven C, Kumar-Singh S. Current insight into molecular mechanisms of Alzheimer disease and their implications for therapeutic approaches. Neurodegener Dis 2007; 4: 349-365.

45. Kawahara $M$, Negishi-Kato $M$, Sakadane $Y$. Calcium dyshomeostasis and neurotoxicity of Alzheimer's beta-amyloid protein. Expert Rev Neurother. 2009; 9: 681-693.

46. Mattson MP, Gary DS, Chan SL, Duan W. Perturbed endoplasmic reticulum function, synaptic apoptosis and the pathogenesis of Alzheimer's disease. Biochem Soc Symp. 2001; 67: 151-162.

47. Kowalska A. Genetic basis of neurodegeneration in familial Alzheimer's disease. Pol J Pharmacol. 2004; 5: 171-178.

48. Shen J, Kelleher RJ 3rd. The presenilin hypothesis of Alzheimer's disease: Evidence for a lossof-function pathogenic mechanism. P Natl Acad Sci USA. 2007; 104; 403-409.

49. Mattson MP, Chan SL. Dysregulation of cellular calcium homeostasis in Alzheimer's disease: Bad genes and bad habits. J Mol Neurosci. 2001; 17: 205-224.

50. Mattson MP. Parkinson's disease: Don'T mess with calcium. J Clin Invest. 2012; 122: 11951198.

51. Skaper SD. Alzheimer's disease and amyloid: culprit or coincidence? Int Rev Neurobiol. 2012; 102: 277-316.

52. Phillips EC, Croft CL, Kurbatskaya K, O'Neill MJ, Hutton ML, Hanger DP, et al. Astrocytes and neuroinflammation in Alzheimer's disease. Biochem Soc Trans. 2014; 42: 1321-1325.

53. Zhang H, Sun S, Wu L, Pchitskaya E, Zakharova O, Fon Tacer K, et al. Store-operated calcium channel complex in postsynaptic spines: A new therapeutic target for Alzheimer's disease treatment. J Neurosci. 2016; 36: 11837-11850.

54. Duncan T, Valenzuela M. Alzheimer's disease, dementia, and stem cell therapy. Stem Cell Res Ther. 2017; 8: 111. 
55. Imm J, Kerrigan TL, Jeffries A, Lunnon K. Using induced pluripotent stem cells to explore genetic and epigenetic variation associated with Alzheimer's disease. Epigenomics. 2017; 9: 1455-1468.

56. Zhou L, Mclnnes J, Wierda K, Holt M, Herrmann AG. Jackson RJ, et al. Tau association with synaptic vesicles causes presynaptic dysfunction. Nat Comm. 2017; 8: 15295.

57. Hamilton LK, Fernandes KJL. Neural stem cells and adult brain fatty acid metabolism: Lessons from the 3xTg model of Alzheimer's disease. Biol Cell. 2018; 110: 6-25.

58. Li P, Lee M, Oh G, Jakubowski JL, Groot D, He Y, et al. Epigenetic dysregulation of enhancers in neurons is associated with Alzheimer's disease pathology and cognitive symptoms. Nat Comm. 2019; 10: 2246.

59. De-Paula VJ, Radanovic M, Diniz BS, Forlenza OV. Alzheimer's disease. Subcell Biochem. 2012; 65: 329-352.

60. Croft CL, Noble W. Preparation of organotypic brain slice cultures for the study of Alzheimer's disease. F1000Res. 2018; 7: 592.

61. Di Paolo G, Kim TW. Linking lipids to Alzheimer's disease: cholesterol and beyond. Nat Rev Neurosci. 2011; 125: 284-296.

62. Wikipedia: Neurofibrillary tangle. $2019 . \quad$ Available from: http://en.wikipedia.org/wiki/Neurofibrillary tangle.

63. Simunkova M, Alwasel SH, Alhazza IM, Jomova K, Kollar V, Rusko M, et al. Management of oxidative stress and other pathologies in Alzheimer's disease. Arch Toxicol. 2019; 93: 24912513.

64. Wikipedia: Amyloid. 2019. Available from: http://en.wikipedia.org/wiki/Amyloid.

65. De Loof A. The cell's self-generated "electrome": The biophysical essence of the immaterial dimension of Life? Commun Integr Biol. 2015; 9: e1197446.

66. Carnevari L, Clark JB. Alzheimer's disease and cholesterol: the fat connection. Neurochem Res. 2007; 32: 739-750. doi: 10.1007/s11064-006-9200-1.

67. Wingo TS, Cutler DJ, Wingo AP, Le NA, Rabinovici GD, Miller BL, et al. Association of earlyonset Alzheimer disease with elevated low-density lipoprotein cholesterol levels and rare genetic coding variants of APOB. JAMA Neurol. 2019; 76: 809-817.

68. Biondi E. Statin-like drugs for the treatment of brain cholesterol loss in Alzheimer's disease. Curr Drug Saf. 2007; 2: 173-176.

69. Karch CM, Goate AM. Alzheimer's disease risk genes and mechanisms of disease pathogenesis. Biol Psychiatry. 2015; 77: 43-51.

70. Wood WG, Li L, Müller WE, Eckert GP. Cholesterol as a causative factor in Alzheimer's disease: a debatable hypothesis. J Neurochem. 2014; 129: 559-572.

71. Hooff GP, Wood WG, Müller WE, Eckert GP. Isoprenoids, small GTPases and Alzheimer's disease. Biochim Biophys Acta. 2010; 1801: 896-905.

72. Hooff GP, Wood WG, Kim JH, Igbavboa U, Ong WY, Muller WE, et al. Brain isoprenoids farnesyl pyrophosphate and geranylgeranyl pyrophosphate are increased in aged mice. Mol Neurobiol. 2012; 46:179-185.

73. Jeong A, Suazo KF, Wood WG, Distefano MD, Li L. Isoprenoids and protein prenylation; implications in the pathogenesis and therapeutic intervention of Alzheimer's disease. Crit Rev Biochem Mol Biol. 2019; 53: 279-310. 
74. Strehler EE, Thayer SA. Evidence for a role of plasma membrane calcium pumps in neurodegenerative disease: Recent developments. Neurosci Lett. 2018; 66: 39-47.

75. Nässel DR, Wegener C. A comparative review of short and long neuropeptide $F$ signaling in invertebrates: Any similarities to vertebrate Y signaling? Peptides. 2011; 32: 1335-1355.

76. Fadda M, Hasakiogullari I, Temmerman L, Beets I, Schoofs L. Regulation of feeding and metabolism by Neuropeptide $F$ and Short neuropeptide $F$ in invertebrates. Front Endocrinol (Lausanne). 2019; 10: 64.

77. Spittaels K, Verhaert P, Shaw C, Johnston RN, Devreese B, Van Beeumen J, et al. Insect neuropeptide $\mathrm{F}$ (NPF)-related peptides: isolation from Colorado potato beetle (Leptinotarsa decemlineata) brain. Insect Biochem Mol Biol. 1996; 26: 375-382.

78. Cerstiaens A, Benfekih L, Zouiten H, Verhaert P, De Loof A, Schoofs L. Led-NPF 1 stimulates ovarian development in locusts. Peptides. 1999; 20: 39-44.

79. Huybrechts J, De Loof A, Schoofs L. Diapausing Colorado potato beetles are devoid of short neuropeptide F I and II. Biochim Biophys Res Commun. 2004; 317: 909-916.

80. Caers J, Peymen K, Van Hiel MB, Van Rompaey L, Van Den Abeele J, Schoofs L, et al. Molecular characterization of a short neuropeptide $F$ signaling system in the tsetse fly, Glossina morsitans morsitans. Gen Comp Endocrinol. 2016; 235: 142-149.

81. Sláma K. Vitamin D1 versus ecdysteroids: Growth effects on cell regeneration and malignant growth in insects are similar to those in humans. Eur J Entomol. 2015; 116: 16-32.

82. De Loof A, Huybrechts R. "Insects do not have sex hormones": A myth? Ge n Comp Endocrinol. 1998; 111: 245-260.

83. Sláma K, Koudelka K, Tenora J, Mathova A. Insect hormones in vertebrates: anabolic effects of 20-hydroxyecdysone in Japanese quail. Experientia. 1996; 52: 702-706.

84. Gorelick-Feldman J, Maclean D, llic N, Poulev A, Lila MA, Cheng D, et al. Phytoecdysteroids increase protein synthesis in skeletal muscle cells. J Agric Food Chem. 2008; 56: 3532-3537.

85. Gorelick-Feldman J, Cohick W, Raskin J. Ecdysteroids elicit a rapid Ca2+ flux leading to Akt activation and increased protein synthesis in skeletal muscle cell. Steroids. 2010; 75: 632-637.

86. Isenmann E., Ambrosio G, Joseph JF, Mazzarino M, de la Torre X, Zimmer P., et al. Ecdysteroids as non-conventional anabolic agent: performance enhancement by ecdysterone supplementation in humans. Arch Toxicol. 2019; 93: 1807-1816.

87. Gilbert LI, Schneiderman HA. Occurrence of substances with juvenile hormone activity in adrenal cortex of vertebrates. Science. 1958; 128: 844.

88. Boerjan B, Sas F, Ernst UR, Tobback J, Lemière F, Vandeguchte MB, et al. Locust phase polyphenism: Does epigenetic precede endocrine regulation? Gen Comp Endocrinol. 2011; 173: $120-128$.

89. Burke YD, Stark MJ, Roach SL, Sen SE, Crowell PL. Inhibition of pancreatic cancer growth by the dietary isoprenoids farnesol and geraniol. Lipids. 1997; 32: 151-156.

90. Popugaeva E, Vlasova O, Bzeprozvanny I. Restoring calcium homeostasis to treat Alzheimer's disease: A future perspective. Neurodener Dis Manag. 2015; 5: 395-398.

91. Sláma K. Insect hormones: More than 50-years after the discovery of insect juvenile hormone analogues (JHA, juvenoids). Terr Arthrop Rev. 2013; 6: 257-333.

92. Sláma K. A new look at the nature of insect juvenile hormone with particular reference to studies carried out in the Czech Republic. Eur J Entomol. 2015; 112: 567-590. 
93. Wu PQ, Yu YF, Zhao Y, Yu CX, Zhi DJ, Qi FM et al. Four novel sesquiterpenoids with their antiAlzheimer's disease activity from Nardostachys chinensis. Org Biomol Chem. 2018; 16: 90389045.

94. Kai ZP, Yin Y, Zhang ZR, Huang J, Tobe SS, Chen SS. A rapid quantitative assay for juvenile hormones and intermediates in the biosynthetic pathway using gas chromatography tandem mass spectrometry. J Chromatogr A. 2018; 1538: 67-74.

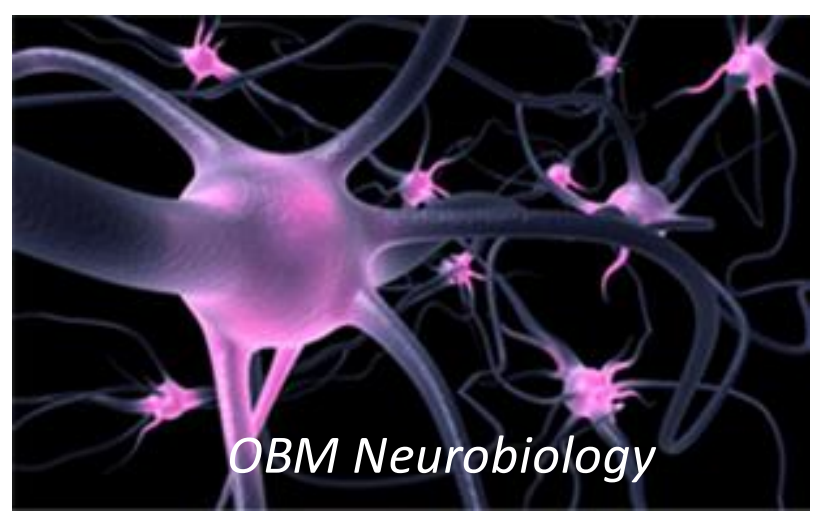

Enjoy OBM Neurobiology by:

1. Submitting a manuscript

2. Joining volunteer reviewer bank

3. Joining Editorial Board

4. Guest editing a special issue

For more details, please visit:

http://www.lidsen.com/journals/neurobiology 